\title{
A Quasi-experimental Study on Effectiveness of Cabbage Leaves Application for Breast Engorgement in Postnatal Mothers at Selected Hospitals, Amritsar, Punjab, India
}

\author{
${ }^{1}$ Rajbir Kaur, ${ }^{2}$ Parvesh Saini
}

\begin{abstract}
Introduction: Breast engorgement occurs in 72 to $85 \%$ of postnatal mothers. One home remedy, i.e., cabbage leaves application, is very effective for engorgement. The objective of the study was to assess the effectiveness of cabbage leaves application on breast engorgement among postnatal mothers.

Materials and methods: The study was conducted in tertiary care medical institute and one private hospital in Amritsar. Totally, 63 (33 in study and 30 in control group) postnatal mothers with engorgement of breast were selected by purposive sampling technique and quasi-experimental design was adopted. Storr breast engorgement scale was used to assess the breast engorgement. The chilled cabbage leaves were applied on engorged breast twice a day for 3 subsequent days. The obtained data were analyzed by using descriptive and inferential statistics like frequency, percentage mean, standard deviation, unpaired t-test, and Chi-squared test.
\end{abstract}

Results: The study result showed that there was reduction in breast engorgement level after the intervention and also showed statistically highly significant difference in between the groups.

Conclusion:There was a significant reduction in severity of breast engorgement among postnatal mothers after application of chilled cabbage leaves. Thus, it was proved to be an effective intervention for severity of breast engorgement. Therefore, this intervention should be promoted as an institutional policy and implemented as a routine care for all postnatal mothers having breast engorgement for reducing severity of breast engorgement.

Keywords: Breast engorgement, Cabbage leaves application, Home remedy, Postnatal mothers.

How to cite this article: Kaur R, Saini P. A Quasi-experimental Study on Effectiveness of Cabbage Leaves Application for Breast Engorgement in Postnatal Mothers at Selected Hospitals, Amritsar, Punjab, India. Curr Trends Diagn Treat 2017;1(2):72-75.

Source of support: Nil

Conflict of interest: None

\footnotetext{
${ }^{1}$ Assistant Professor, ${ }^{2}$ Professor

1,2Department of Obstetrics and Gynecology, Sri Guru Ram Das College of Nursing, Amritsar, Punjab, India
}

Corresponding Author: Rajbir Kaur, Assistant Professor Department of Obstetrics and Gynecology, Sri Guru Ram Das College of Nursing, Amritsar, Punjab, India, e-mail: getyashraj2006@gmail.com

\section{INTRODUCTION}

The birth of a baby is an important event in any family. ${ }^{1}$ It is, therefore, important that for a mother to have a healthy baby, she gives her baby the best nutrition. Breast milk is the best food for babies as breastfed babies are generally healthier than formula-fed ones. ${ }^{2}$ The mammary gland is a milk-producing gland, which is composed largely of fat. It is a complex network of branching ducts and sac-like structures called lobules, which produce milk. Breast tissue fluid drains through the lymphatic into the lymph nodes located in the axilla and behind the sternum. ${ }^{3}$ Immediately after birth, the mother produces colostrum, a yellow sticky fluid secreted by breast that provides nutrition and protects against infection.

Breast engorgement usually happens when the breasts switch off from colostrum to mature milk. ${ }^{4}$ As milk production increases, overdistention of the alveoli causes the milk-secreting cells to become flattened and occlude the capillary blood circulation surrounding the alveolar cells. Congestion contributes to edema and obstructs lymphatic drainage of the breasts, stagnating the system that rids the breasts of toxins and bacteria, and leading to mastitis. In very severe cases, there can be numbness or tingling of the hands from pressure on the nerves. In addition, a protein called the feedback inhibitor of lactation accumulates in the mammary gland during milk stasis. It acts as a major trigger of apoptosis, that causes involution of the milk-secreting gland, collapse of the alveolar structures, and the cessation of milk production. ${ }^{5}$ Breast engorgement and infection are responsible for puerperal pyrexia. ${ }^{6}$ Engorgement may lead to mastitis. ${ }^{7,8}$ Subareolar tissue resistance also increases during engorgement and results in latching difficulty. ${ }^{9}$ According to the Academy of Breastfeeding Medicine Protocol Committee and Berens, ${ }^{10}$ breast engorgement is defined as "the swelling and distension of the breasts, usually in the early days of initiation of lactation, caused by vascular dilatation as well as the arrival of the early milk."

Cabbage leaves have been used for centuries as a folk remedy for a wide variety of ailments and received much renewed interest from lactation professionals over the past 10 years. It contains a natural mixture of ingredients that helps to decrease tissue congestion by dilating local 
capillaries in mild, moderate, and severe discomfort. ${ }^{11}$ Ayers $^{12}$ stated that this natural mixture of ingredients from Mother Nature's Kitchen helps decrease tissue congestion by dilating (opening) local capillaries (small blood vessels), which improves the blood flow in and out of the area, allowing the body to re-absorb the fluid trapped in the breasts. Cabbage may also have a type of drawing or wicking action that helps move trapped fluid. Elizabeth ${ }^{13}$ stated that cabbage leaf contains singrin rapine, magnesium, oxalate, and many other nutrients. It is also believed to have antibiotic as well as anti-irritant properties.

In addition, the review of literature and investigator's own experience, while being posted in clinical settings, motivated the investigator to use cold cabbage leaves for relieving breast engorgement. Moreover, it is a home remedy and mothers who are not able to get treatment from hospitals during puerperal period can derive benefits from this remedy.

Hence, this study is aimed to assess the effectiveness of chilled cabbage leaves application on breast engorgement among postnatal mothers admitted in the postnatal ward at selected hospitals, Amritsar, Punjab, India.

\section{MATERIALS AND METHODS}

A quasi-experimental study was conducted to assess the effectiveness of chilled cabbage leaves on engorgement of breast. The present study was conducted at selected hospitals in Amritsar, Punjab from December 15, 2012 to January 15, 2013. A total of 63 postnatal mothers having complaints of engorgement of breast were selected for the study. The purposive sampling technique was used to collect the data. The tool used for the study was demographic variables and Storr breast engorgement scale to collect the data. The technique was explained to the subjects and consent was also obtained. Demographic variables and breast engorgement level were assessed for both experimental and control groups.

Experimental group (33) mothers received chilled cabbage leaves compresses for relieving engorgement. During the study period, two subjects had discontinued the intervention due to discharge on request from the hospital and one subject suffered from reaction (redness) from cabbage leaves. Hence, the dropout rate of the study was $1 \%$ (3). Cabbage leaves were refrigerated for approximately 20 to 30 minutes. The temperature for chilled cabbage leaves was $18^{\circ} \mathrm{C}$ as assessed by a lotion thermometer and placed on the engorged breast. Bra was put on the top of the leaves to keep them in place. The cold cabbage leaves were applied twice a day for 3 subsequent days. It was done six times on each subject. The duration of each intervention was 30 minutes. Intervention was given by principal investigator herself. Postintervention scores of breast engorgement were assessed with the same scale at the end of the 3rd day. Conceptual framework adopted for the study was modified Roy's adoption model. The data obtained were processed in MS Excel sheet. The statistical analysis was performed using the software STRATA.

\section{Inclusion Criteria}

- Postnatal mothers with breast engorgement

- Willing to participate in the study

\section{Exclusion Criteria}

- Mothers with allergy to sulfa drugs and cabbage

- Mothers with soft breast; mothers receiving lactation suppressant

- Mothers with infection in the breast, breast abscess, mastitis, broken skin of breast, and bleeding or cracked nipples

\section{Data Collection Tools}

- Part I: Demographic data: it contains the age, education, family income per month, habitat, gravida, type of delivery, day of delivery, type of feeding, site of breast engorgement, and condition of nipple.

- Part II: Storr scale for assessment of engorgement.

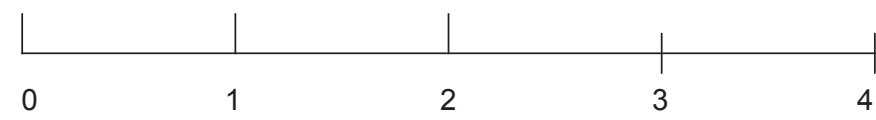

$0-$ Normal and no pain

1-Breast beginning to feel full and mild pain

2-Breast heavy, slightly warm, and moderate pain

3-Breast warm and heavy and severe pain

4-Breast very hard and worst pain

\section{RESULTS}

The obtained data were analyzed by using descriptive and inferential statistics. The two groups were found homogeneous with regard to all demographic and obstetric variables as analyzed by chi-squared test.

Table 1 and Graph 1 show that the highest mean score $(3.63 \pm 0.49)$ was obtained for pretest, whereas the lowest

Table 1: Breast engorgement score of experimental group before and after cabbage leaves application

\begin{tabular}{llllll}
\hline & & \multicolumn{3}{c}{ Paired } \\
$n=30$ & Mean & SD & Mean \% & t-test & $p$-value \\
\hline Pretest finding & 3.63 & 0.49 & 90.83 & 1.034 & $0.305 \mathrm{NS}$ \\
Day 1 & 3.13 & 0.78 & 78.33 & 5.39 & $<0.001^{\text {** }}$ \\
Day 2 & 1.90 & 0.76 & 47.50 & 18.24 & $<0.001^{\text {** }}$ \\
Day 3 & 0.37 & 0.61 & 9.17 & 30.67 & $<0.001^{\text {** }}$ \\
\hline
\end{tabular}

**Highly significant at the level of <0.001; NS: Nonsignificant; SD: Standard deviation; Range: Minimum score 0; Maximum score 5 




Graph 1: Breast engorgement score of experimental group before and after cabbage leaves application

mean score was $(0.37 \pm 0.61)$. Hence, the differences in breast engorgement among postnatal mothers were highly significant in experimental group.

Table 2 shows that paired $t$-test indicates significant differences in breast engorgement among postnatal mothers that were observed only during the third day when compared with days 1 and 2 .

In Table 3, the analysis shows that the significant difference in the mean breast engorgement score was observed only on day 3 in the control group, but the significant difference in the mean breast engorgement score was observed from day 1 in the experimental group among postnatal mothers after cabbage leaves application. Also, the highly significant difference was observed on days 2 and 3 .

The paired t-test value was significant at the level of $p<0.001$. This shows that the application of cabbage leaves on engorged breast was very effective. There was no statistical significant association between posttest breast engorgement scores with demographic variables.

\section{DISCUSSION}

The majority of the postnatal mothers were primiparous [21 (70\%)] and $9(30 \%)$ were multipara. Supporting these findings is a study conducted by Ruba ${ }^{14}$ that found that
Table 2: Breast engorgement score of control group before and after cabbage leaves application

\begin{tabular}{llllll}
\hline $\begin{array}{l}\text { No. of days for } \\
\text { application }(n=30)\end{array}$ & Mean & SD & Mean \% & Paired \\
\hline Pretest finding & 3.50 & 0.51 & 87.50 & 1.034 & \multicolumn{1}{l}{$0.305 \mathrm{NS}$} \\
Day 1 & 3.47 & 0.51 & 86.67 & 1.00 & $0.326 \mathrm{NS}$ \\
Day 2 & 3.53 & 0.63 & 88.33 & -0.24 & $0.813 \mathrm{NS}$ \\
Day 3 & 2.83 & 0.43 & 70.83 & 4.33 & $<0.000^{*}$ \\
\hline
\end{tabular}

*Significant at the level of <0.05; NS: Nonsignificant; SD: Standard deviation

primigravida mothers were more prone to develop breast engorgement than multipara substantially.

The findings of pretreatment scores by using breast engorgement scale were found to be moderately painful in $10(30 \%)$ and severely painful in $20(70 \%)$ postnatal women. One study conducted by Joy and Kharde ${ }^{15}$ supported these findings where 1 subject $(0.33 \%)$ complained of slight pain, $9(30 \%)$ moderate, and 20 (66.67) complained of severe pain.

The findings of Roberts ${ }^{16}$ and Roberts et al ${ }^{17}$ also support this study because they reported that chilled cabbage leaves and cold gel packs were equally effective in reducing breast engorgement and pain in postpartum mothers.

This study was also supported by the finding of Ruba, ${ }_{1}^{14}$ who conducted a study to assess the effectiveness of cabbage leaves application on breast engorgement among postnatal mothers and found that application of cabbage leaves to relieve breast engorgement is very effective.

A study was conducted in Australia by Roberts et $\mathrm{al}^{18}$ to compare the effectiveness of chilled and room temperature green cabbage leaves in reducing discomfort due to breast engorgement among postnatal mothers. Mothers reported less pain with both the conditions, and the majority of the mothers preferred cold cabbage leaves.

Arora et $\mathrm{al}^{19}$ also compared the efficacy of cold cabbage leaves and hot and cold applications in the treatment of breast engorgement. They found that the cold cabbage leaves and hot and cold applications were both effective in decreasing breast engorgement.

Table 3: Comparison of pre- and postbreast engorgement test scores in experimental and control group

\begin{tabular}{|c|c|c|c|c|c|c|}
\hline \multirow{2}{*}{$\begin{array}{l}\text { Day }(n=30 \\
+30=60)\end{array}$} & \multicolumn{2}{|c|}{ Control group } & \multicolumn{2}{|c|}{ Experimental group } & \multirow[b]{2}{*}{$t$-value } & \multirow[b]{2}{*}{$p$-value } \\
\hline & Mean & $S D$ & Mean & $S D$ & & \\
\hline Baseline & 3.50 & 0.51 & 3.63 & 0.49 & -1.03 & $0.305 \mathrm{NS}$ \\
\hline Day 1 & 3.47 & 0.51 & 2.90 & 0.66 & 3.72 & $<0.001^{*}$ \\
\hline Day 2 & 3.53 & 0.63 & 1.57 & 0.57 & 12.71 & $<0.001^{*}$ \\
\hline Day 3 & 2.83 & 0.75 & 0.43 & 0.50 & 14.59 & $<0.001^{*}$ \\
\hline $\mathrm{F}$ & 9.14 & & 192.78 & & & \\
\hline$p$ & $<0.001$ & & $<0.001$ & & & \\
\hline
\end{tabular}

*Significant at the level of<0.05; NS: Nonsignificant; SD: Standard deviation 
Snowden et $\mathrm{al}^{20}{ }^{20}$ who reviewed research studies to determine the effects of several interventions to relieve symptoms of breast engorgement among breastfeeding women, found that cabbage leaves were effective in the treatment of this painful condition. The results of the current study also showed that significant improvements in breast engorgement were observed postintervention $(\mathrm{p}<0.001)$.

\section{CONCLUSION}

The study finding revealed that there was significant reduction of breast engorgement with chilled cabbage leaves application among postnatal mothers. Thus, it also proved that chilled cabbage leaves application can be effective in preventing further breast complications. It is a home remedy and a cost-effective method. Therefore, this intervention may be implemented as a routine care for all postnatal mothers having breast engorgement for reducing severity of breast engorgement.

\section{ACKNOWLEDGMENTS}

The authors are grateful to the postnatal women who participated in this study. The authors are also thankful to the statistician for performing the statistical analyses for this study.

\section{REFERENCES}

1. Chopra M. Breast milk is best but what about HIV. MRC News. 2006. [cited 2006 Dec]. Available from: http://www. mrc.ac.za/mrcnews/dec2006/breast.htm.

2. Padubidri V, Anand E, editors. A text book of obstetrics. 1st ed. New Delhi: BL Publications; 2006. pp. 390-391.

3. Dutta DC, Konar H. Textbook of obstetrics including perinatology and contraception. 6th ed. Calcutta: New Central book agency (P) Ltd; 2004. p. 149-150, 451-453.

4. Campbell S, Lees C. Obstetrics by 10 teachers. 17th ed. London: Arnold; 2009. Available from: http//www.Gobookee.com/ ten teacher-obstetric-17th ed.

5. Smith MK. New perspectives on engorgement. Leaven 19992000 Dec-Jan;35(6):134-136.
6. Giugliani ER. Common problems during lactation and their management. J Pediatr (Rio J) 2004 Nov;80(Suppl 5):S147-S154.

7. Mass M. Breast pain: engorgement, nipple pain and mastitis. Clin Obstet Gynecol 2004 Sep;47(3):676-682.

8. World Health Organization. Mastitis: causes and management. Geneva: WHO; 2000. [cited 2000 Jan 9]. Available from: http://www.who.int/nutrition/publications/infantfeeding/ WHO__NHD.

9. Humenick SS, Hill PD, Anderson MA. Breast engorgement: patterns and selected outcomes. J Hum Lact 1994 Jun;10(2): 87-93.

10. Academy of Breastfeeding Medicine Protocol Committee; Berens P. ABM clinical protocol \#20: engorgement. Breastfeed Med 2009 Jun;4(2):111-113.

11. Smith S. Cabbage leaves for treatment and prevention of breast engorgement. Available from: http://www.breastfeeding. com.

12. Ayers JF. The use of alternative therapies in the support of breastfeeding. J Hum Lact 2000 Feb;16(1):52-56.

13. Elizabeth B. Cabbage leaves for breast engorgement. 2012. [cited 2012 Aug 16]. Available from: http://www.midwifeinfo.com.

14. Ruba R. Effectiveness of cabbage leaves application to relieve breast engorgement. Nightingale Nurs Times 2009 Dec;5(9): 48-51.

15. Joy J, Kharde SN. A study to evaluate the effectiveness of chilled cabbage leaves application for relief of breast engorgement in volunteered postnatal mothers who are admitted in maternity ward of selected hospital in Belgaum. Int J Biol Med Res 2016;7(3):5655-5659.

16. Roberts KL. A comparison of chilled cabbage leaves and chilled gel packs in reducing breast engorgement. J Hum Lact 1995 Mar;11(1):17-20.

17. Roberts KL, Reiter M, Schuster D. Effect of cabbage leaves extract on breast engorgement. J Hum Lact 2001 Sep;14(3): 231-236.

18. Roberts KL, Reiter M, Schuster D. A comparison of chilled and room temperature cabbage leaves in treating breast engorgement. J Hum Lact 1995 Sep;11(3):191-194.

19. Arora S, Vatsa M, Dhadwal V. A comparison of cabbage leaves vs hot \& cold compression for the treatment of breast engorgement. Indian J Community Med 2008 Jul;33(3): 160-162.

20. Snowden HM, Renfrew MJ, Woolridge MW. Treatment for breast engorgement during lactation. Cochrane Database Syst Rev 2001 Apr;2:CD000046. 